\title{
FORMATIVE OF METAL CONTENTS IN ELECTRONIC WASTE MOBILE PHONE CIRCUIT BOARDS
}

\author{
Sarwar Muhammad Tariq ${ }^{1 *}$, Zhan HanHui ${ }^{1}$, Yang Jiaxin ${ }^{2}$ \\ ${ }^{I *}$ School of Environment Sciences and Spatial Informatics, China University of Mining and Technology, Xuzhou, \\ P.R China 221116; \\ ${ }^{I}$ School of Chemical Engineering and Technology, China University of Mining and Technology, Xuzhou, P.R China \\ 221116; \\ ${ }^{*}$ Corresponding author Sarwar Muhammad Tariq, \\ e-mail: tariqsarwar98@yahoo.com; zhanhhh@263.net; jasmine525bm@163.com;
}

Received December 2019; Accepted January 2020; Published February 2020;

DOI: https://doi.org/10.31407/ijees10.127

\begin{abstract}
Advancement in electronic technology makes their life span shortened thus causes a huge number of electronic waste mobile phone circuit boards (WPCBs) to be produced, which presents the new global environmental challenges. Recycling of these electronic WPCBs is a positive step towards not only protect the environment but also for resource recovery. This work carried out for determining the highly valuable metal contents in electronic waste mobile phone circuit boards and finds a high-precision measurement method for the betterment of recycling technologies. $\mathrm{HNO}_{3}$-HF$\mathrm{HClO}_{4}$ pretreatment digestion method and ICP-MS multi-analysis showed the highest copper proportion of about $83.31 \%$ in used mobile phone boards. Through the analysis of the precision data, it is verified that the method is reliable and has good reproducibility.
\end{abstract}

Keywords: Waste Mobile Phone Circuit Board (WPCBs); Digestion; Metal content 